\title{
MITIGATING THE INFLUENCE OF DENSE OIL FIRES ON FREE-SPACE OPTICAL COMMUNICATION
}

\author{
Thoalfiqar Ali Zaker \\ Department of Physics \\ College of Education \\ Al-Hamdaniya University \\ Al-Hamdaniya, Nineveh, Iraq, 41006 \\ thoalfiqar.physics@uohamdaniya.edu.iq \\ Talib Zeedan Taban ${ }^{1}$ \\ talibmosawi@gmail.com \\ Firas S. Mohammed \\ fsphd@uomustansiriyah.edu.iq \\ ${ }^{1}$ Department of Physics \\ College of Sciences \\ Mustansiriyah University \\ AlMustansiriyah,Baghdad, Iraq,10052
}

\begin{abstract}
This study estimates the performance of a free space optical system (FSO) affected by air pollutants from oil fires. Simulations are performed to evaluate the reliability of optical propagation according to the length of the FSO channels under two beam angle angles. The proposed FSO system parameters such as the Q-factor, BER and reception capacity are successfully used to reduce channel loss. Results demonstrate that the proposed FSO link performs satisfactorily when the divergence angle is $1 \mathrm{mrad}$ and the distance is from $0.5 \mathrm{~km}$ to $0.9 \mathrm{~km}$. Q-factor and receiving power decrease when the divergence angle of beam increases to $2 \mathrm{mrad}$, and a link is achieved when the distance is from $0.5 \mathrm{~km}$ to $0.7 \mathrm{~km}$. The eye diagram is used to evaluate and confirm the quality of received data. An eye opening is observed at $0.5 \mathrm{~km}$ for both divergence angles. Then, the eye completely closes at $1 \mathrm{~km}$ for $2 \mathrm{mrad}$, thereby degrading the performance. Therefore, these results can be conducted for similar systems optimization options by applying our analysis.
\end{abstract}

Keywords: Laser system, Free space optics, dense oil fires, BER, Q-Factor.

DOI: $10.21303 / 2461-4262.2020 .001242$

\section{Introduction}

Several scientific researchers have shown that air pollutants formed by petroleum fires can degrade air quality, impair visibility and harm sensitive ecosystems. Serious pollutants, such as $\mathrm{CO}, \mathrm{CO}_{2}, \mathrm{NO}_{x}, \mathrm{SO}_{2}$ and airborne particulates, are generated when petroleum is burned [1-5]. Radio communication systems do not function reliably under these conditions due to the limitations in capacity and scalability [6]. Free-space optical (FSO) signal is used to enable transmission and receiving of signals without significant loss [7]. It has the ability and durability to transfer large amounts of energy. However FSO is negatively affected by weather conditions and turbulence. Fog clouds and fires play a harmful role by optical mitigation energy transferred into free ground space and thus reducing link availability and reliability [8]. FSO links offer a high-speed, secure and license-free communication system contrary to radiofrequency links [9]. The reliability of optical propagation is influenced by local weather conditions. Therefore, the operation parameters of FSO communication systems are modified depending on the atmospheric conditions. A hybrid free-space optical (FSO)/radio frequency (RF) communication systems are example of combining diversity scheme [10]. Other Related work considers multiple parallel FSO links which can support data rates. Multi-input, multi-output system was used and proposed over two rings with specified radius [11]. Air pollutants affect the performance of optical systems depending on their concentrations, dosages, exposure times and other factors [12, 13]. Increased attenuation coefficient and its impact on the received photovoltaic energy, bit error rate (BER) and Q factor under heavy fog 
(smoke and columns) during oil fires [14, 15]. As shown in Fig. 1, the presence of particles of aerosols and dense gases in smoke and flames may cause severe disturbances in the spread of light signals in the FSO channel [16].

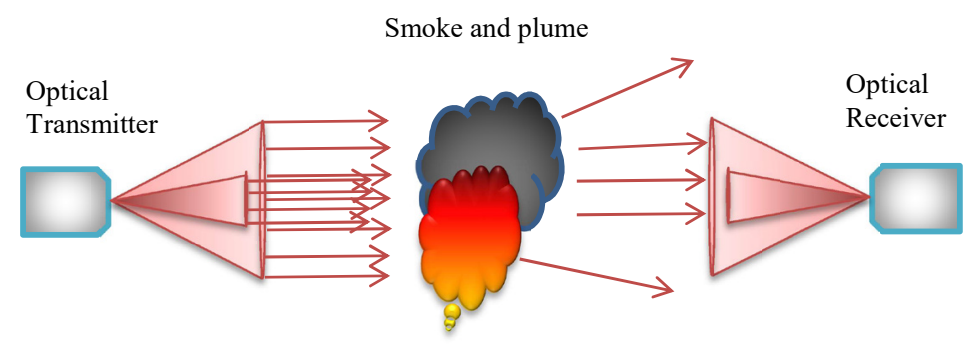

Fig. 1. Block diagram of an FSO system with different divergence angles

The use of transmission beam spacing is a technique to help align and track FSO links - [17, 18] two adaptive beam control methods, whereby the transmitter deviation angle of the transmitter is set to (i) maximizing link availability or (ii) reducing transmitter power while maintaining target link availability. In second case, the choice of control modes is highly dependent on communication scenarios [17]. Another study, investigated the quality and feasibility of the communication link, considering the impact of beam divergence on the polarization shift keying (PolSK) modulation under various weather conditions. It is shown that PolSK subdues the effects of increase in beam divergence, attenuation factor, and further extends the communication range [18]. In this study, the change in system parameters that contribute to the optics of a reliable FSO link is tested to obtain the best system specifications in regions that suffer from frequent petroleum fires. The aim of the study is to demonstrate the effect of gases and other pollutants resulting from oil fires on the performance of the optical communication system in the air and to find appropriate solutions that can reduce this effect. The parameters used in this case are transmitter divergence angle and link distance. The adaptive FSO systems are designed using the OptiSystem programme.

\section{Simulation system design}

In order to, investigate the real performance of FSO system under the smoke influence. Simulation environment can be used easily for defining the system components and scenario. Opti-system program able to operate independently based on the realistic modeling of FSO system. Beers-Lambert Law is used to describe the attenuation of laser power through the atmospheric channel [19]:

$$
\tau_{R}=\frac{P_{R}}{P_{O}}=e^{-\sigma R},
$$

$\tau_{R}$ is transmittance at range $R, P_{R}$ is the received laser power, $P_{0}$ is the transmitted laser power, and $\sigma$ is an attenuation coefficient.

The attenuation coefficient $\sigma(\mathrm{dB} / \mathrm{km})$ of an optical signal due to the scattering of smoke can be calculated by [14]:

$$
\sigma_{\left(\frac{d B}{k m}\right)}=\frac{17}{V_{k m}}\left[\frac{\lambda}{\lambda_{0}}\right]^{-q(\lambda)},
$$

$V_{k m}$ is the visibility of an FSO link, $\lambda_{0}$ is the maximum wavelength of the solar band, $\lambda$ is the wavelength of laser signal, and $q(\lambda)$ is the coefficient referring to the size of distributed particles,

$$
q(\lambda)=0.8467 \lambda-0.5212
$$

Fig. 2 shows the block diagram of the simulation design of the proposed FSO system. The system contains a transmitter, an air channel, and a receiving unit [20]. The proposed transmitter 
includes a $20 \mathrm{~dB}$ laser diode at $1500 \mathrm{~nm}$, a semi-random random bit generator, a non-zero pulse generator (NRZ) and a Mach-Zehnder modulator. The modified light signals are then propagated through the heavy fog channel (smoke and columns) and are received by the single-beam FSO receiver. The receiver consists of icy diodes and a low-pass Bessel filter used to filter unwanted high-frequency signals at a cut-off frequency of 0.75 signal bitrate. The last element in the receiver is the $3 \mathrm{R}$ optical regenerator that is used to regenerate electrical signals of the original bit sequence for BER analysis. The simulation is visualized using an optical power metre to measure the receiving power. Electrical carriers and BER analysers are also utilized to calculate the BER value and Q-factor and display the eye diagram. Table 1 lists the simulation parameters.

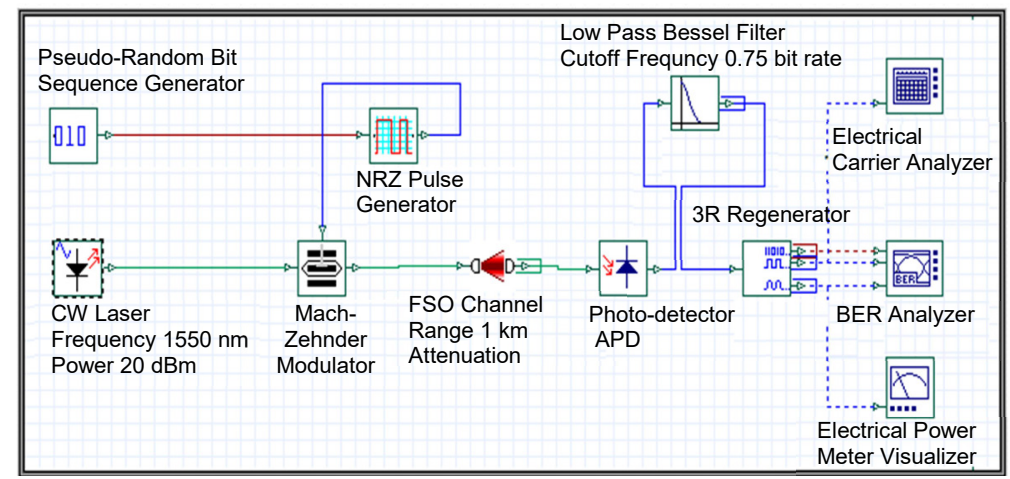

Fig. 2. Block diagram of the simulation setup of the proposed FSO link

Table 1

Simulation parameters for FSO link

\begin{tabular}{cc}
\hline Parameters & Values \\
\hline "Transmitted Power (dBm)" & 20.0 \\
"Transmitter diameter (cm)" & 5.00 \\
"Transmitter efficiency" & 0.50 \\
"Receiver sensitivity (dBm)" & -20.0 \\
"Wavelength (nm)" & 1550 \\
"Receiver diameter (cm)" & 20.0 \\
"Receiver efficiency" & 0.50
\end{tabular}

The parameters values depends on the actual propagation state of the signal-carrying system.

\section{Results and Discussion}

Simulations are performed to evaluate the performance of the proposed FSO system for ground communications. Tables 2, 3 show the changes in the $Q$-factor, BER and reception capacity according to the length of the FSO channels under two beam angle angles. For commercial communications applications, $\mathrm{BER}=10-9$ is a required typical value [21].

As shown in the Tables 2, 3, the proposed system works satisfactorily when the difference angle is $1 \mathrm{mrad}$ and the distance is from 0.7 to $0.9 \mathrm{~km}$. A BER $10-9$ rate is achieved for $Q=6 . Q$ which measures the transmit signal quality factor in terms of signal-to-noise ratio (SNR). $\mathrm{SNR}$ or $\mathrm{S} / \mathrm{N}$ is defined as the ratio of signal power to noise power that spoils the signal. A ratio greater than 1:1 indicates a signal over noise. The maximum SNR assumes an ideal input signal [21]. Specifically, the higher $Q$ factor value, the better signal-to-noise ratio (SNR), and thus the lower the probability of bit errors [22]. $Q$-factor and receiving power decrease when the divergence angle of beam is increased to $2 \mathrm{mrad}$, and a link is achieved when the distance is from 
0.6 to $0.8 \mathrm{~km}$ due to scattering caused by the smoke and plume aerosols [23]. It is noted that the $Q$-factor decreases significantly with increase in distances with acceptable performance levels (above 6), agree with [18, 24]. The eye diagram is used to evaluate and confirm the quality of received data. The diagram is also used to evaluate the signal-to-noise ratio SNR and the BER. Fig. 3, $\boldsymbol{a}-\boldsymbol{d}$ shows the eye diagram for the lowest and highest values of the link distance for the divergence angles of 1 and $2 \mathrm{mrad}$.

Table 2

Performance analysis of the link at the divergence angle of transmitter of $1 \mathrm{mrad}$

\begin{tabular}{cccc}
\hline Link distance km & Q-Factor & BER & Receiving Power dBm \\
\hline 0.5 & 58.5 & $1 \mathrm{E}-1$ & -21 \\
0.6 & 34 & $1.14 \mathrm{E}-26$ & -31 \\
0.7 & 19.8 & $-1.12 \mathrm{E}-087$ & -40 \\
0.8 & 11.7 & $4.47 \mathrm{E}-032$ & -49 \\
0.9 & 7 & $6 \mathrm{E}-013$ & -58 \\
1 & 4 & $2 \mathrm{E}-005$ & -67
\end{tabular}

Table 3

Performance analysis of the link at the divergence angle of transmitter of $2 \mathrm{mrad}$

\begin{tabular}{cccc}
\hline Link distance km & Q-Factor & BER & Receiving Power dBm \\
\hline 0.5 & 31.5 & 8 E-22 & -32 \\
0.6 & 17.6 & 3.7 E-07 & -42 \\
0.7 & 10.25 & 3.25 E-025 & -52 \\
0.8 & 6 & 7 E-01 & -61 \\
0.9 & 3.23 & 0.0004 & -69 \\
1 & 0 & 1 & -77
\end{tabular}

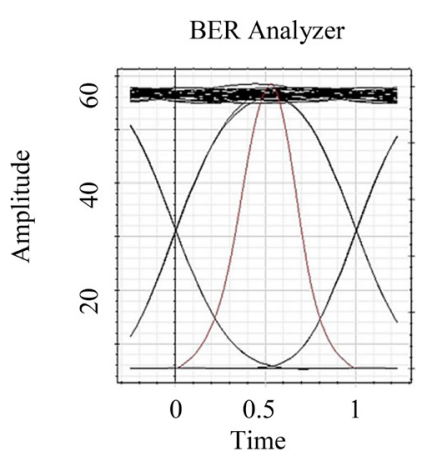

$a$

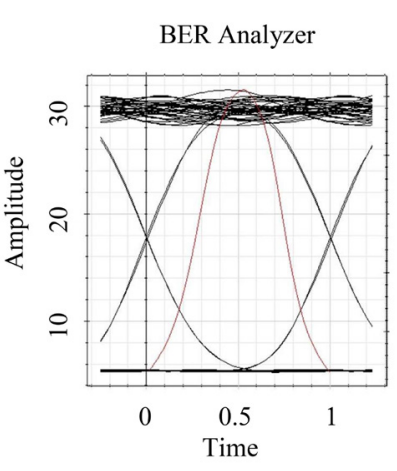

$b$

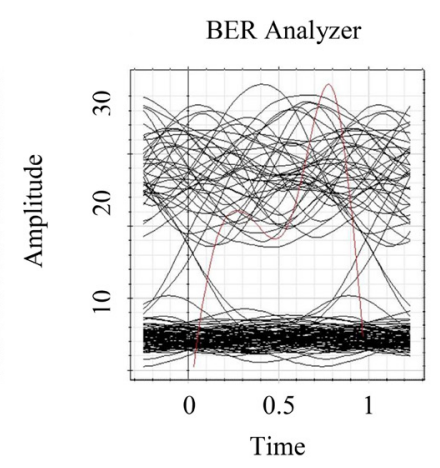

$c$

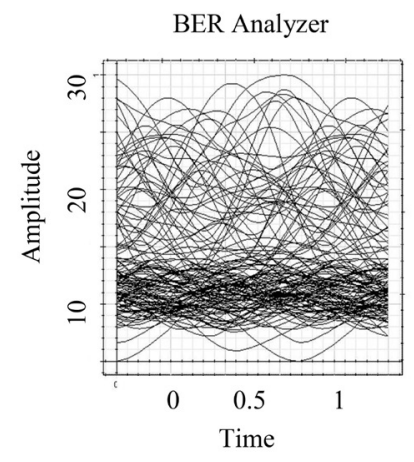

$d$

Fig. 3. Eye diagram performance of FSO at:

$a-0.5 \mathrm{~km}, 1 \mathrm{mrad} ; b-0.5 \mathrm{~km}, 2 \mathrm{mrad} ; c-1 \mathrm{~km}, 1 \mathrm{mrad} ; d-1 \mathrm{~km}, 2 \mathrm{mrad}$

An eye opening is observed at $0.5 \mathrm{~km}$ for both divergence angles ( $1 \mathrm{mrad}, 2 \mathrm{mrad})$ as shown in Fig. 3, $\boldsymbol{a}, \boldsymbol{b}$ respectively. Then, the eye partially closes at $1 \mathrm{~km}$ for $1 \mathrm{mrad}$ as shown in Fig. 3, . Finally, the eye completely closes at $1 \mathrm{~km}$ for $2 \mathrm{mrad}$ as shown in Fig. 3, $\boldsymbol{d}$, thereby degrading the performance, agree with $[17,25]$. 
The proposed solutions improve the performance of FSO link by utilize several parameters of same system parts without adding a new components.

This study implements modifications on the beam divergence angle and link distances of optical wireless system under smoke clouds arise from oil well fires (for the first time). Some other researches either investigated another effects such as rain, dust, sand or make essential modifications by adding complex parts.

This work should follow by practical study to strengthening the findings. There is no restrictions can be imposed on the use of the results.

The Oil-producing Countries suffer from frequent oil well fires. That's why, its welcoming suck kind of research. The most common problem is not getting security license for the practical investigations.

\section{Conclusions}

In this study, the proposed FSO system parameters are successfully used to minimize channel loss due to atmospheric pollutants formed by petroleum fires. The results demonstrate that the proposed FSO link performs satisfactorily when the divergence angle is $1 \mathrm{mrad}$ and the distance is from $0.7 \mathrm{~km}$ to $0.9 \mathrm{~km}$. $Q$-factor and receiving power decrease when the divergence angle of beam increases to $2 \mathrm{mrad}$, and a link is achieved when the distance is from $0.6 \mathrm{~km}$ to $0.8 \mathrm{~km}$. Therefore, these results can be conducted for similar systems optimization options by applying our analysis.

\section{Acknowledgements}

The authors would like to thank Mustansiriyah University and Al-Hamdaniya University for their support in this work.

\section{References}

[1] Khan, L. U. (2017). Visible light communication: Applications, architecture, standardization and research challenges. Digital Communications and Networks, 3 (2), 78-88. doi: https://doi.org/10.1016/j.dcan.2016.07.004

[2] Awoyemi, B., Maharaj, B., Alfa, A. (2017). Optimal resource allocation solutions for heterogeneous cognitive radio networks. Digital Communications and Networks, 3 (2), 129-139. doi: https://doi.org/10.1016/j.dcan.2016.11.003

[3] Malik, A., Singh, P. (2015). Free Space Optics: Current Applications and Future Challenges. International Journal of Optics, 2015, 1-7. doi: https://doi.org/10.1155/2015/945483

[4] Wang, J., Zou, N., Wang, D., Irie, K., Iha, Z., Namihira, Y. (2012). Experimental study on visible light communication based on LED. The Journal of China Universities of Posts and Telecommunications, 19, 197-200. doi: https://doi.org/10.1016/s10058885(11)60422-6

[5] Muralikrishna, I. V., Manickam, V. (2017). Environmental Management. Elsevier, 664.

[6] Son, I. K., Mao, S. (2017). A survey of free space optical networks. Digital Communications and Networks, 3 (2), 67-77. doi: https://doi.org/10.1016/j.dcan.2016.11.002

[7] Haq, A. F. M. S., Yuksel, M. (2019). Weather limited short-range in-band full-duplex free-space optical transceiver. Free-Space Laser Communications XXXI. doi: https://doi.org/10.1117/12.2513909

[8] Awan, M. S., Horwath, L. C., Muhammad, S. S., Leitgeb, E., Nadeem, F., Khan, M. S. (2009). Characterization of Fog and Snow Attenuations for Free-Space Optical Propagation. Journal of Communications, 4 (8). doi: https://doi.org/10.4304/jcm. 4.8.533-545

[9] Perez, J., Zvanovec, S., Ghassemlooy, Z., Popoola, W. O. (2014). Experimental characterization and mitigation of turbulence induced signal fades within an ad hoc FSO network. Optics Express, 22 (3), 3208. doi: https://doi.org/10.1364/oe.22.003208

[10] Liang, H., Gao, C., Li, Y., Miao, M., Li, X. (2019). Analysis of selection combining scheme for hybrid FSO/RF transmission considering misalignment. Optics Communications, 435, 399-404. doi: https://doi.org/10.1016/j.optcom.2018.11.042

[11] Savojbolaghchi, H., Sadough, S. M. S., Dabiri, M. T., Ansari, I. S. (2019). Generalized channel estimation and data detection for MIMO multiplexing FSO parallel channels over limited space. Optics Communications, 452, 158-168. doi: https://oi.org/ 10.1016/j.optcom.2019.07.017

[12] Meng, Y.-Y., Wilhelm, M., Rull, R. P., English, P., Ritz, B. (2007). Traffic and outdoor air pollution levels near residences and poorly controlled asthma in adults. Annals of Allergy, Asthma \& Immunology, 98 (5), 455-463. doi: https://doi.org/10.1016/ s1081-1206(10)60760-0 
[13] Majumdar, A. K. (2015). Advanced Free Space Optics (FSO). A Systems Approach. Springer. doi: https://doi.org/10.1007/9781-4939-0918-6

[14] Ijaz, M., Ghassemlooy, Z., Pesek, J., Fiser, O., Le Minh, H., Bentley, E. (2013). Modeling of Fog and Smoke Attenuation in Free Space Optical Communications Link Under Controlled Laboratory Conditions. Journal of Lightwave Technology, 31 (11), 1720-1726. doi: https://doi.org/10.1109/j1t.2013.2257683

[15] Saleem, Z., Khan, N., Ishaq, W., Altaf, M. (2006). Free Space Optical (FSO) Link Design Under Diverse Weather Conditions. Proceedings of the 5th WSEAS Int. Conf. on Microelectronics, Nanoelectronics, Optoelectronics. Prague, 97-104.

[16] Maranghides, A., Mell, W. E., Walton, W. D., Johnsson, E. L., Bryner, N. P. (2006). Free space optics communication system testing in smoke and fire environments. doi: https://doi.org/10.6028/nist.ir.7317

[17] Mai, V. V., Kim, H. (2018). Adaptive beam control techniques for airborne free-space optical communication systems. Applied Optics, 57 (26), 7462. doi: https://doi.org/10.1364/ao.57.007462

[18] Rajeev, M., Mathew, G. A., Krishnan, P. (2019). Analysis of beam divergence on free space optical link using polarization shift keying technique. Optical Engineering, 58 (04), 1. doi: https://doi.org/10.1117/1.oe.58.4.046109

[19] Weichel, H. (Ed.) (1990). Laser Beam Propagation in the Atmosphere. Bellingham.

[20] Shaulov, G., Patel, J., Whitlock, B., Mena, P., Scarmozzino, R. (n.d.). Simulation-Assisted Design of Free Space Optical Transmission Systems. MILCOM 2005 - 2005 IEEE Military Communications Conference. doi: https://doi.org/10.1109/milcom. 2005.1605797

[21] Jahangir Alam, S. M., Alam, M. R., Guoqing, H., Mehrab, M. Z. (2014). Improvement of Bit Error Rate in Fiber Optic Communications. International Journal of Future Computer and Communication, 3 (4), 281-286. doi: https://doi.org/10.7763/ijfcc.2014. v3.312

[22] Majumdar, A. K., Ricklin, J. C. (2008). Free-Space Laser Communications: Principles and Advances. Springer. doi: https:// doi.org/10.1007/978-0-387-28677-8

[23] Mohammed, F. S., Shaker, F. K. (2019). The Impact of Oil Well Fires on the Free Space Optical Systems. Al-Mustansiriyah Journal of Science, 29 (3), 113. doi: https://doi.org/10.23851/mjs.v29i3.628

[24] Singh, M. (2018). Improved Performance Analysis of Free Space Optics Communication Link under Rain Conditions using EDFA Pre-amplifier. Journal of Optical Communications, 39 (2), 241-246. doi: https://doi.org/10.1515/joc-2016-0136

[25] Mai, V. V., Kim, H. (2019). Mitigation of Effects of Angle-of-Arrival Fluctuation and Pointing Error on Airborne Free-Space Optical Systems. Optical Fiber Communication Conference (OFC) 2019. doi: https://doi.org/10.1364/ofc.2019.w2a.40 